\title{
A formação de professores no ensino superior: relações com a avaliação institucional
}

\author{
Cassia Ferri; Blaise Keniel da Cruz Duarte; Adair De Aguiar Neitzel; Mônica Zewe \\ Uriarte; Nilmar de Souza*
}

Resumo. Este artigo discute o impacto na atuação docente do programa de formação continuada desenvolvido em uma instituição localizada na Região Sul do Brasil, a Universidade do Vale do Itajaí - Univali. O objetivo é identificar se há alguma relação entre a atuação do professor e a adesão dele à formação continuada. A metodologia utilizada é quali-quantitativa. Os instrumentos de coleta de dados foram: a) média da carga horária do professor no Programa de Formação Continuada da Univali; b) média da nota resultante do Programa de Avaliação Institucional da Univali que afere a atuação docente; $c$ ) temáticas cursadas pelos professores. A coleta de dados se refere ao período compreendido entre o primeiro semestre de 2011 e o primeiro semestre de 2017. Ao todo foram analisados os dados de 69 professores da instituição de um conjunto de cerca de mil professores, tendo sido selecionados somente aqueles que participaram da formação continuada em todos os semestres nesse intervalo e foram avaliados pelos discentes nesses mesmos semestres. 0 aporte teórico principal utilizado para discussão dos dados foi Nóvoa (2000), Sá et al.(2017), Franco (2016), entre outros. Como resultado, sinalizamos que o índice de adesão dos docentes da amostra ao Programa de Formação Continuada da Univali vem aumentando, apesar de a carga horária mínima de formação exigida pela instituição ter diminuído ao longo dos anos. Identificamos que $100 \%$ dos docentes selecionados concentraram carga horária nas temáticas pedagógicas. A partir dos dados coletados pelo Programa de Avaliação Institucional, constatamos que a média atribuída pelos estudantes à atuação dos docentes integrantes da amostra varia entre 8,3 e 8,7. Dos 69 docentes selecionados, 95,66\% possuem média superior a 7 ; três possuem média inferior a sete e nenhum docente possui média inferior a seis.

Palavras-chave: educação superior; formação de professores; avaliação institucional.

\section{LA FORMACIÓN DE PROFESORES EN LA ENSEÑANZA SUPERIOR: RELACIONES CON LA EVALUACIÓN INSTITUCIONAL}

Resumen. Este artigo discute el impacto del Programa de Formación Continuada de una institución del Sur del Brasil, UNIVALI, en la actuación docente, identificando si hay alguna relación entre la actuación del profesor y la formación continuada. La metodología utilizada es cualitativa y cuantitativa. Los instrumentos de colecta de datos fueron: a) promedio del cargo de horas del profesor del Programa de Formación Continuada; b) promedio de la nota resultante en la Evaluación Institucional que se le adhiere a la

\footnotetext{
* Universidade do Vale do Itajaí (UNIVALI), Brasil.
} 
actuación docente; c) temáticas cursadas por los profesores. La colecta de datos se refiere al período del 2011-1 al 2017-1. Al todo fueron analizados los datos de 69 profesores de la institución de un conjunto total de mil profesores. El criterio para selección del profesor fue haber participado de la formación en todos los semestres y, durante ese tiempo haber sido evaluado por parte de los estudiantes en esos mismos semestres. El aporte teórico principal utilizado para la discusión de los datos fue Nóvoa (2000), Sá et al.(2017), Franco (2016), entre otros. Como resultado señalamos que el índice de participación de los docentes en el Programa de Formación Continuada está aumentando. A pesar de que el cargo de horas mínimo de formación exigido por la instituição haya disminuido a lo largo de los años, la adhesión docente al programa aumentó. Identificamos que 100\% de los docentes hicieron más horas en las temáticas pedagógicas. Sobre la evaluación institucional el promedio de evaluación de la actuación docente establecida por los alumnos varía entre 8,3 y 8,7. De los 69 docentes que forman parte de esta muestra, sólo tres de ellos poseen promedio inferior a siete y superior a seis, o sea, el 95,66\% poseen promedio superior a 7 . Ningún docente posee promedio inferior a seis.

Palabras clave: educación superior; formación de profesores; evaluación institucional.

TEACHING TRAINING IN HIGHER EDUCATION: ITS RELATIONSHIP WITH INSTITUTIONAL ASSESSMENT

Abstract. This article discusses the impact of the Continuing Education Program of an institution in the South of Brazil, UNIVALI, on teacher's practices, identifying whether there is any relationship between these practices and continuing education. Qualitative and quantitative methods were used in this research. The data collection instruments were: a) average number of hours that the teachers spent in the Continuing Education Program; b) average scores in the Institutional Assessment, which assesses teaching practice; and c) the subjects taught by the teachers. Data were collected in the period 2011-1 to 2017-1. Data were analyzed for 69 teachers, out of approximately one thousand teachers of the institution. The selection criteria was that the teacher must have participated in the training in all the semesters during this time period, and have received an assessment score by the students during those same semesters. The main theoretical background used to discuss the data was based on Nóvoa (2000), Sá et al.(2017), and Franco (2016), among other authors. In the results, we see that the level of participation of the teachers in the Continuing Education Program has increased. Although the number of training hours required by the institution has decreased over the years, the adhesion of teachers to the program has increased. We identified that $100 \%$ of the teachers had increased the number of hours spent on pedagogical topics. Concerning the institutional assessment, the scores for teaching practice attributed by the students ranged from 8.3 to 8.7. Of the 69 teachers who made up this sample, only three scored below 7 and above 6. In other words, $95.66 \%$ scored more than 7. None of the teachers scored below 6 .

Keywords: higher education; teaching training; institutional assessment 


\section{INTRODUÇÃO}

Acredito que é possível instaurar grupos de reflexão pedagógica dentro das universidades, que conduzam pouco a pouco a instaurar rotinas de debate, de supervisão, de formação interpares (Nóvoa, 2000, p. 134).

Nóvoa (2000) nos convida a refletir sobre a rotina na universidade, sobre a necessidade de a docência se realizar no exercício da reflexão, do debate, da troca de ideias. Sabemos que ensinar na Educação Superior passa por alguns dilemas, como a formação técnica de docentes que não se prepararam para a docência, mas para o exercício de uma outra profissão. Diante de uma sala de aula, esse profissional se questiona: Como ensinar? E ele descobre que a docência exige mais que o domínio de conteúdo. Como resolver os problemas cotidianos? Ele se depara com a organização de planos de ensino, planejamento das aulas, uso de diferentes estratégias em sala de aula, elaboração e correção das avaliações, e o desafio está posto: é preciso aprender a ensinar. E o que Nóvoa suscita na epígrafe é que essa aprendizagem necessita se dar na coletividade, no diálogo, na relação com os pares, na partilha.

Uma pesquisa realizada na Universidade do Vale do Itajaí, Brasil, (Ferri; Duarte; Neitzel; Uriarte; Sousa, 2017) revelou que os professores mais bem avaliados pelos discentes com relação a sua atuação em sala de aula são os licenciados, ou seja, aqueles que se prepararam para ser professores. De acordo com a mesma pesquisa, os saberes da docência são aprendidos não apenas na ação profissional, pois apesar das experiências docentes serem fundamentais para a própria constituição da profissionalidade, há saberes próprios do magistério que constituem a expertise da educação, suas bases teóricas, habilidades próprias da profissão de professor.

Mas como agir com os profissionais que se colocam como professores sem a aquisição desses saberes? Sá, Quadros, Mortimer, Silva e Talim (2017, p. 627) sinalizam que "Para exercer essa atividade, eles provavelmente mobilizam saberes da prática dos professores que tiveram durante seus percursos como estudantes e de sua própria experiência acumulada no exercício da docência". À medida que exercem a docência, entendem a necessidade de melhoria das práticas em sala de aula e que ela depende da aprendizagem no exercício do magistério, mas também de uma aprendizagem reflexiva, que ocorra em serviço, num determinado espaço de discussão para a elaboração de significados sobre o ensinar. Partimos do pressuposto segundo o qual essa 
aprendizagem reflexiva para a docência no contexto da Educação Superior ocorre na formação continuada, entendida como espaço de encontro e troca produtiva de conhecimento com os pares.

A formação continuada para professores da Educação Superior é uma proposta da Lei de Diretrizes e Bases da Educação Nacional (Brasil, 1996). Alinhando-se à essa legislação, a Univali possui um programa de formação continuada que propõe "diálogos e troca de experiências [que] sirvam como elementos motivadores para o desenvolvimento profissional, pessoal e coletivo do corpo docente" (Pryjma e Oliveira, 2017, p. 9). Segundo esses autores, é no confronto com os pares que o professor pode reconstruir e transformar seu pensar e agir profissional. A pesquisa desenvolvida por Pryjma e Oliveira (2017, p. 6) revela que as maiores limitações sinalizadas pelos docentes na Educação Superior estão em aprender sozinho, "pois envolvem questões vinculadas à reflexão isolada da aprendizagem profissional, caracterizada pela ausência de sistematização e limitada à perspectiva individual do professor". Diante dessa afirmação, entendemos a necessidade de a universidade propor grupos de reflexão, como afirma Nóvoa (2000).

Quando os programas de formação continuada promovem a oportunidade de confrontação e de elaboração do conhecimento profissional, eles não apenas ampliam conhecimentos ou habilidades próprias da profissão de professor, passando a oferecer domínio sobre o repertório dos saberes da docência, mas também dão espaço para as experiências narradas, estudos de caso, uma prática associada à pesquisa e à reflexão crítica. E "a reflexão crítica necessita ser encarada como direção prioritária para que se desenhe a trajetória do desenvolvimento profissional dos professores" (Pryjma e Oliveira, 2017, p. 8). Nesse sentido, a aula não é um momento individual, de cada professor, pois há uma política institucional que dá suporte às práticas pedagógicas de acordo com o Projeto Pedagógico Institucional - PPI.

A formação continuada passa a ser, portanto, o espaço no qual o professor reconhece a necessidade de articulação dos seus saberes com aqueles de natureza pedagógica e metodológica. Segundo Nóvoa (2000, p. 134), "Quando o professor deslocar a atenção exclusivamente dos 'saberes que ensina' para as pessoas a quem esses 'saberes vão ser ensinados', vai sentir a necessidade imperiosa de fazer uma reflexão sobre o sentido do seu trabalho". Uma vez confrontados esses saberes, as possibilidades de pensar a teoria a partir da prática e vice-versa são maiores, a dinâmica na sala de aula foge das tentativas e erros, evidenciando uma compreensão mais bem elaborada dos processos de ensinar e aprender. 


\section{PERCURSO METODOLÓGICO}

Esta é uma pesquisa quali-quantitativa cujo foco é a formação continuada dos docentes na Universidade do Vale do Itajaí, Univali, instituição situada em Santa Catarina, Região Sul do Brasil. Buscamos discutir o impacto do programa institucional de formação continuada na atuação docente, identificando se há relação entre os indicadores da atuação docente, resultantes da pesquisa de percepção aplicada pelo programa de avaliação institucional entre os estudantes, e a carga horária da formação continuada. Cruzamos dados da formação continuada com os da avaliação institucional para apurar os impactos da formação. Os instrumentos de coleta de dados foram: a) média da carga horária do professor na formação; b) média resultante das notas atribuídas pelos estudantes aos indicadores da avaliação institucional que aferem a atuação docente; c) temáticas cursadas pelos professores no Programa de Formação Continuada da Univali.

A coleta de dados se refere ao período entre o primeiro semestre de 2011 e o primeiro semestre de 2017. Ao todo foram analisados os dados de 69 professores da instituição de um conjunto de cerca de mil professores. O critério de seleção foi o professor ter participado da formação em todos os semestres nesse intervalo de tempo e ter recebido avaliação por parte dos discentes nesses mesmos semestres, portanto, foram excluídos os professores que deixaram de participar da formação em algum semestre e/ou que não foram avaliados. Esse critério afastou professores novos, tendo em vista que o recorte temporal é de 12 semestres. A análise deu-se por meio do cruzamento de dados das fontes citadas, a triangulação metodológica.

\section{O PROGRAMA DE FORMAÇÃO CONTINUADA DA UNIVALI}

O ensino com pesquisa tornou-se uma prerrogativa da universidade porque a forma como o conhecimento é gerado e divulgado mudou com as tecnologias. Nesse sentido, conceber a formação do professor ultrapassa o utilitarismo e centra-se em uma proposta que o leve a pensar sobre as concepções que fundamentam sua ação, a refletir sobre acertos e fracassos, a trocar experiências, transformando a profissão docente em um "processo simultaneamente criativo e desafiador" (Borba, 2002, p. 7).

Nóvoa nos convida a pensar sobre a formação docente e os pressupostos nos quais ela precisa se assentar: "O que eu quero significar é que a questão da formação docente não é puramente pedagógica ou metodoló- 
gica, a questão é muito mais vasta e remete para um novo equilíbrio entre as funções tradicionais da Universidade: o ensino e a investigação" (Nóvoa, 2000, p. 133).

Em busca desse equilíbrio, a Universidade do Vale do Itajaí implantou, em julho de 2000, o Programa de Formação Continuada Docente como um processo sistemático de orientação e acompanhamento pedagógico. Foi organizado como um fórum de discussão em torno da concepção de educação que se adota na universidade, e para que os saberes próprios da profissionalidade docente fossem debatidos. O programa - previsto em calendário acadêmico - visa a oferecer ao professor a oportunidade de se desenvolver como um profissional investigativo que sabe lidar com a complexidade do mundo contemporâneo, tendo em vista a multiplicidade de saberes e fazeres que envolvem a docência. Até 2014, organizou-se em torno de três eixos:

Saberes da Docência: oferecia temáticas que favoreciam um trabalho de reflexão em torno das práticas pedagógicas e acerca da identidade docente. Promovia o debate de questões relevantes que impulsionassem a busca de saberes sobre a docência e que possibilitassem ao docente enfrentar as questões que cotidianamente desafiam sua prática.

Política Institucional: voltado à compreensão da organização institucional, dos objetivos e metas da IES na área do ensino, da pesquisa e da extensão. Também eram contempladas temáticas que diziam respeito às políticas públicas e aos rumos da Educação Superior no país.

Cultura e Formação Geral: pautado em assuntos de interesse cultural e humanístico, tinha como objetivo ampliar a formação cultural e geral dos docentes. Tendo em vista que a formação é percebida como um espaço de convivência, de trocas culturais produtivas e que o homem aprende por meio das interações com seus pares, eram propostas temáticas que ampliassem as vivências em grupo, modos de ver e olhar o entorno.

O Programa de Formação Continuada Docente da Univali, nesse intervalo, produziu nove cadernos de ensino que apresentavam as orientações teórico-metodológicas adotadas pela instituição, assim como textos que provocavam a discussão sobre a docência, entre eles o registro de experiências exitosas desenvolvidas no âmbito institucional.

A partir de 2014, o programa foi reestruturado, centrando suas temáticas em torno do eixo Docência no Ensino Superior e ajustando o foco para questões voltadas aos projetos pedagógicos de curso e, consequentemente, aos processos que envolvem o ensino e a aprendizagem. 
Realizado como formação em exercício, esse programa é uma atividade obrigatória nos meses de fevereiro e julho. A carga horária a ser cumprida pelo professor varia: até 2011, devia corresponder à carga horária de ensino (isto é, quem tinha 30 horas no ensino, cumpria 30 horas na formação); a partir de 2014, a regulamentação da carga horária passou a ser feita por meio de instrução normativa que estabelece faixas diferenciadas de horas a serem cumpridas.

\section{TABELA 1}

\section{Carga horária no Programa de Formação Continuada Docente da Univali}

\begin{tabular}{|c|c|c|}
\hline \multirow{2}{*}{ Ano } & $\begin{array}{c}\text { Carga horária } \\
\text { do professor }\end{array}$ & $\begin{array}{c}\text { Carga horária } \\
\text { mínima de FC }\end{array}$ \\
\hline \multirow{2}{*}{2014} & de $12 \mathrm{~h}$ a $40 \mathrm{~h}$ & $20 \mathrm{~h}$ \\
\cline { 2 - 3 } & menos de $12 \mathrm{~h}$ & $16 \mathrm{~h}$ \\
\hline \multirow{2}{*}{2015} & Até 8 horas & 04 h \\
\cline { 2 - 3 } & de $8 \mathrm{~h}$ a $12 \mathrm{~h}$ & $08 \mathrm{~h}$ \\
\cline { 2 - 3 } & de 12 a $20 \mathrm{~h}$ & $16 \mathrm{~h}$ \\
\cline { 2 - 3 } & acima de $20 \mathrm{~h}$ & $20 \mathrm{~h}$ \\
\hline
\end{tabular}

Fonte: UNIVALI, Vice-Reitoria de Graduação, Gerência de Ensino e Avaliação, 2017

A instrução normativa de 2014 estabelece ainda que ao professor compete fazer uma carga horária mínima nas oficinas do curso de graduação a que esteja ligado (oficinas relativas ao Projeto Pedagógico) e nas denominadas oficinas institucionais, tendo em vista a necessidade de garantir ao corpo docente um espaço de discussão sobre os saberes da docência e de participação no Projeto Pedagógico do Curso, porque é essa discussão que Ihe permitirá compreender a dinâmica e as diretrizes da instituição. Observamos que, apesar de a carga horária mínima obrigatória de formação ter diminuído ao longo dos anos, o índice de adesão ao programa aumentou no período de 2011 a 2017.

Este dado nos permite inferir que a adesão ao programa de formação continuada da instituição vem aumentando, o que revela a compreensão da necessidade de socializar saberes e da incorporação dessa ação na cultura acadêmica. Percebemos, pelo índice de participação docente, o processo formativo se constituindo não por palestras episódicas, mas por temáticas que fortalecem a política institucional segundo eixos, objetivos e metas, com aderência dos docentes. Segundo Stano (2015, p. 279), quando se oferece a possibilidade de um programa de formação com essas características, "via 
compartilhamento de experiências docentes, o professor se exercita no olhar do outro. É ao outro, componentes-ouvintes-pensantes de sua prática, que o professor se mostra ao olhar".

\section{GRÁFICO 1 \\ Índice de participação no Programa de Formação Continuada Docente da Univali}

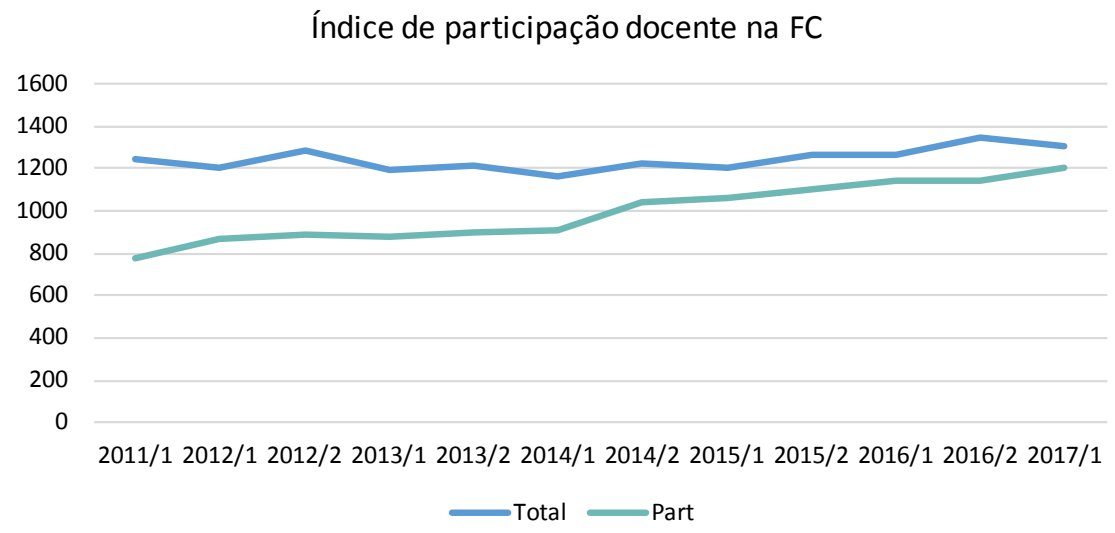

Fonte: UNIVALI, VRG - GEA/2017

Castro e Navarro (2017), ao discutirem os pontos fortes e frágeis na Educação Superior privada na América Latina, apontam que a qualidade acadêmica não está correlacionada ao lucro, e defendem a necessidade de apoio público para qualificar ainda mais os cursos oferecidos. Essa qualificação, segundo os pesquisadores, passa pela preparação de materiais educativos e pela formação de professores. Um programa de formação continuada é importante porque mantém aberto um espaço para interlocução com os pares e para o compartilhamento de experiências docentes que podem contribuir para a melhoria do exercício da profissão.

\section{ANÁLISE DE DADOS: CRUZANDO A AVALIAÇÃO INSTITUCIONAL COM A FORIMAÇÃO CONTINUADA}

Para Nóvoa (2000), a cultura universitária se situa num espaço de equilíbrio entre liberdade de ação e regulação (entendida como ranqueamento, classificação, avaliação) que não pode perder de vista a formação de pessoas e a produção da cultura e da ciência. Isto significa pensar sobre os dispositivos de regulação universitária de forma a preservar sua autonomia, utilizando-os não para acirrar a competitividade, mas para ampliar a qualidade da Educação Superior. "Creio que temos de imaginar formas mais abertas e 
participadas de regulação, evitando as tendências corporativas e instaurando processos que valorizem as duas grandes missões da Universidade: formar pessoas e produzir cultura e ciência" (Nóvoa, 2000, p. 137).

Estudo de Sá et al. sobre a formação de professores na Educação Superior (2017, p. 627) traz também algumas questões importantes sobre o tema. Para os autores, a formação tem um caráter precioso porque hoje o aluno chega à universidade com um perfil muito diferente de anos atrás, e a concepção de educação mudou. Para ser bem sucedido, já não basta ao professor ter domínio do conteúdo, e isso exige "novas abordagens e estratégias de intervenção pedagógica que busquem valorizar a participação do aluno e que também trabalhem, de forma integrada", componentes curriculares interdependentes, dentre eles, os conceitos, os procedimentos e as atitudes. Os autores lembram que a maioria dos professores universitários é formada em “programas de pós-graduação cujo foco está na formação de pesquisadores em seus campos específicos e sem exigência quanto à formação pedagógica" (2017, p. 628).

Essa é uma realidade das universidades públicas e privadas e 0 estabelecimento de um programa de formação continuada para docentes tem sido balizado como uma possibilidade real de qualificar a Educação Superior. Na universidade investigada, como já mencionado, o programa é obrigatório e os professores necessitam fazer uma carga horária mínima, por semestre, de acordo com sua carga horária de trabalho, conforme apontado na Tabela 1.

\section{GRÁFICO 2}

\section{Média de horas dos professores na Formação Continuada Docente} da Univali (2011-2017)

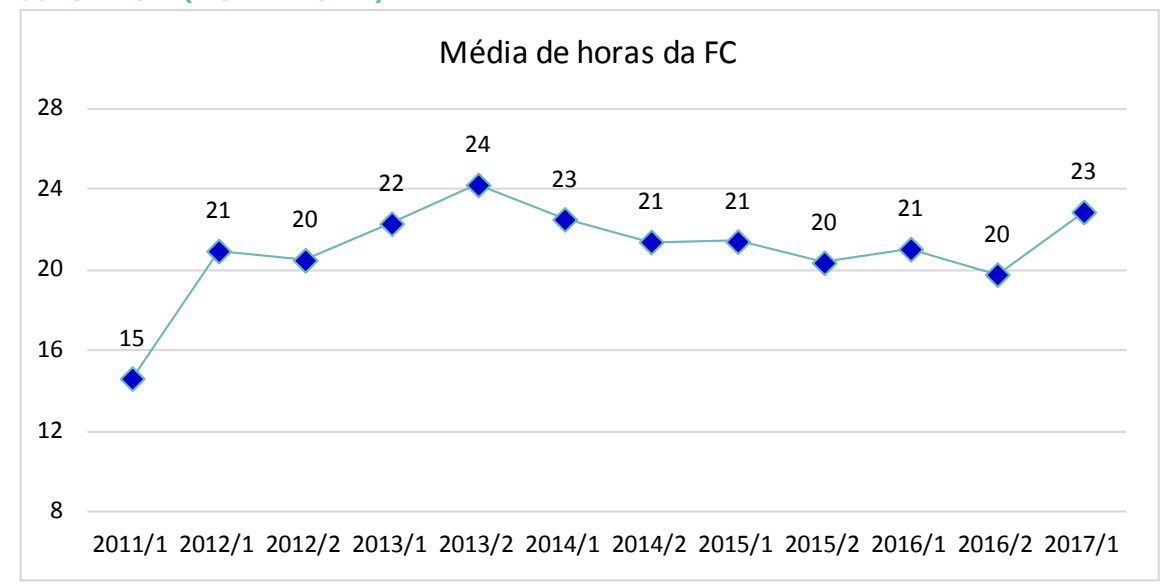

Fonte: UNIVALI, VRG - GEA/2017 
No gráfico 2, constatamos que a média de horas cumpridas por semestre pelos docentes da instituição a partir do primeiro semestre de 2012 oscila de 21 a 24 horas, mas, quando analisamos a carga horária da formação continuada cumprida pelo grupo de 69 professores investigados, percebemos que 11 atingiram média maior que 30 horas de formação. Saindo da esfera das médias, ao analisarmos a carga horária de cada docente desse grupo, identificamos que todos, entre 2011 e 2017, pelo menos em um semestre, completaram mais de 30 horas de formação. Isto significa que o movimento de participar da formação continuada para esse grupo experiente de professores está além de ser uma obrigação institucional, há um envolvimento, um compartilhamento de experiências que os aproxima e os estimula a integrar-se ao programa, entendendo-o como parte de "seu itinerário profissional, suas histórias de vida, seus modos de ver e ser no mundo" (Stano, 2015, p. 285).

Quanto à média da atuação docente resultante da avaliação feita pelo discente, observamos no Gráfico 3 que está situada entre 8,3 e 8,7. Embora os indicadores constantes do questionário de autoavaliação adotado pela Univali não contemplem todos os aspectos que envolvem uma sala de aula e sua dinâmica, o instrumento dá conta de algumas demandas institucionais e tem como referência o Plano de Desenvolvimento Institucional - PDI. Essa associação aumenta a relevância do questionário, pois, conforme defendem Nunes, Duarte, Pereira (2017, p. 374), a avaliação institucional "Articulada ao planejamento, pode se constituir em uma ação efetiva que assegure 0 desenvolvimento de uma instituição de ensino superior". Se a avaliação pode sinalizar formas de melhoria do ensino, pode também sinalizar ao professor juízos que the permitam autoestimar-se.

\section{GRÁFICO 3}

Média da atuação docente no Programa de Avaliação Institucional da Univali (2011-2017)

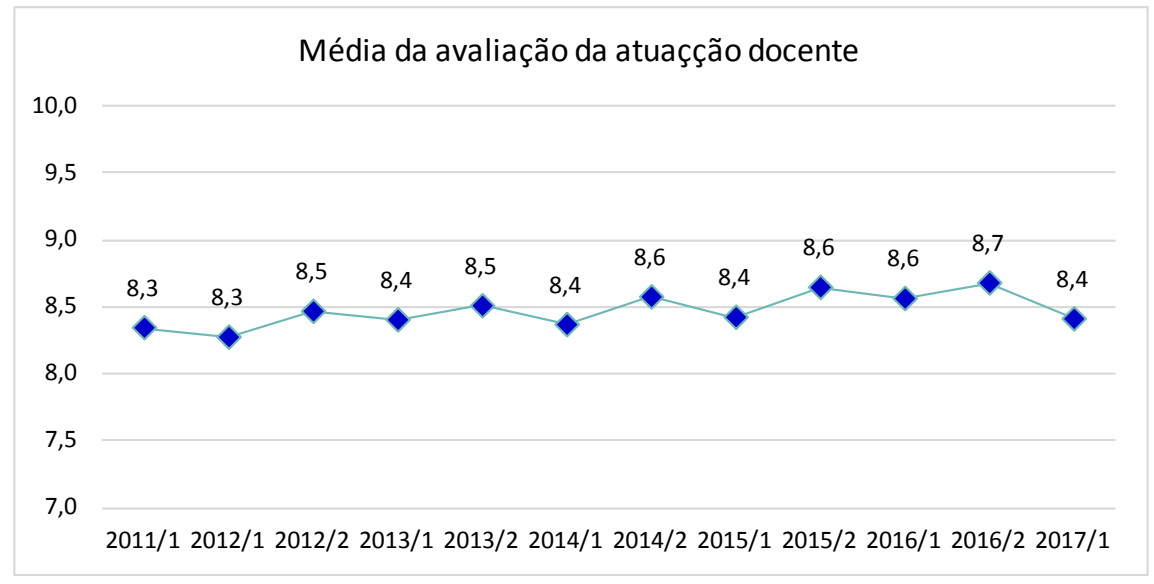

Fonte: UNIVALI, VRG - GEA/2017 
A atuação docente é avaliada pelos estudantes com base nos seguintes indicadores: pontualidade, domínio de conteúdo, esclarece dúvidas, utiliza linguagem clara, adota o plano de ensino como referência, discute resultados das avaliações, mantém clima de trabalho produtivo. Esse processo avaliativo é fator relevante para o desempenho profissional e a atuação do professor em sala de aula; ele sinaliza à instituição questões que podem impactar a qualidade da educação e ampliar não só a aprendizagem dos acadêmicos como modificar sua relação com a universidade. Segundo Gatti (2000, p. 94), "avaliações são processos que devem gerar estímulo, servir de alavanca, servir à mudança e à transformação e não serem utilizados para rebaixamento de autoestima, seletividade, punição, diminuição de valia". Pelo Gráfico 3, não é possível identificar os casos de média baixa, eles estão diluídos. Torna-se necessária, portanto, uma análise mais acurada dos resultados. Assim, devemos observar a Tabela 02, quanto à avaliação discente sobre a atuação dos docentes que compõem o grupo focalizado: nesta tabela podemos perceber que 10 professores receberam média acima de oito; um, abaixo de 7.

\section{TABELA 2}

\section{Relação entre média da atuação e carga horária na Formação Continuada} Docente da Univali entre o grupo de professores constante da amostra

\begin{tabular}{|c|c|}
\hline $\begin{array}{c}\text { Avaliação } \\
\text { Institucional } \\
2011-2017\end{array}$ & $\begin{array}{c}\text { Formação } \\
\text { Continuada } \\
2011-2017\end{array}$ \\
\hline 8,77 & 33,33 \\
\hline 7,80 & 34,00 \\
\hline 6,91 & 32,50 \\
\hline 8,51 & 35,33 \\
\hline 8,27 & 34,67 \\
\hline 8,57 & 41,67 \\
\hline 8,06 & 30,67 \\
\hline 8,40 & 32,67 \\
\hline 8,48 & 33,00 \\
\hline 8,81 & 47,70 \\
\hline 9,12 & 31,00 \\
\hline
\end{tabular}

Fonte: UNIVALI, VRG - GEA/2017

Dos 69 docentes que fazem parte desta amostra, 95,66\% possuem média superior a 7 ; três possuem média inferior a 7 . Nenhum docente possui média inferior a seis e os três em questão possuem média de carga horária na formação continuada igual ou superior a 24 horas. 


\section{TABELA 3 \\ Menor avaliação institucional e carga horária na Formação Continuada

\begin{tabular}{|c|c|}
\hline $\begin{array}{c}\text { Avaliação } \\
\text { Institucional } \\
2011-2017\end{array}$ & $\begin{array}{c}\text { Formação } \\
\text { Continuada } \\
2011-2017\end{array}$ \\
\hline 6,73 & 24,00 \\
\hline 6,91 & 26,33 \\
\hline 6,91 & 32,50 \\
\hline
\end{tabular}

Fonte: UNIVALI, VRG - GEA/2017

Que conclusões podemos apreender deste cenário? Podemos inferir que a formação continuada impacta a atuação em sala de aula ao contribuir para que o professor planeje suas aulas com estratégias de ensino diversificadas, atendendo a diferentes necessidades e possibilitando outros recursos de aprendizagem? Ou ainda, que a formação continuada ao oferecer temáticas pedagógicas auxilia o docente a adotar uma linguagem clara em sala de aula, ampliando as possibilidades de aprendizagem e promovendo a aproximação teórica e prática com o mundo do trabalho, facilitando a compreensão dos conceitos e a elaboração do conhecimento? Como os dados acima não são suficientes para nos conduzir a uma resposta, passamos a investigar de quais temáticas esses docentes haviam participado na formação continuada. Até o primeiro semestre de 2014 , eles poderiam optar por qualquer temática da programação, o que Ihes oferecia a liberdade de participar de temáticas voltadas para extensão, cultura, pesquisa, formação específica da sua área, educação estética ou outra. No segundo semestre de 2014, o Programa de Formação Continuada Docente da Univali foi submetido a uma reorganização de seus eixos: o professor passou a ter que cumprir, no mínimo, 4 horas no curso discutindo o Projeto Pedagógico e 4 horas nas temáticas intituladas institucionais; as demais, ele poderia escolher de um rol de oficinas organizadas pelos apoios pedagógicos de cada área sob a supervisão da Vice-Reitoria de Graduação.

\section{TEMÁTICAS FREQUENTADAS NA FORMAÇ̃̃O CONTINUADA}

A formação continuada, com o objetivo de ampliar as possibilidades da ação pedagógica e das práticas curriculares, oferece parâmetros para que os docentes adotem uma atitude crítica diante de seu trabalho, frente à elaboração de um plano de ensino, de planejamentos de aulas, avaliações, estratégias, entre outros. 
Esses parâmetros estão identificados com o eixo Saberes da Docência e influenciam diretamente a prática do professor em sala, as estratégias que seleciona, a avaliação que aplica, o seu jeito de se relacionar com a turma, enfim, as atitudes que potencializam a reflexão sobre a concepção de educação adotada pela universidade, sobre a prática e interferem na competência profissional.

As temáticas pedagógicas permitem ao professor elaborar um planejamento que proponha ações para romper com "a passividade dos seus alunos em sala, como o uso de recursos para tornar a aula mais dinâmica, a exposição de situações que serão utilizadas para introduzir as explicações acerca do tema a ser estudado e ações para favorecer o trabalho dos alunos com essas ideias" (Sá et al., 2017, p.630).

Até o primeiro semestre de 2014, muitas eram as temáticas ofertadas pelo Programa de Formação Continuada Docente da Univali. Contudo, apesar de influenciarem as escolhas, de ampliarem o repertório cultural do professor, não eram especificamente consideradas pedagógicas. Essas temáticas diziam respeito aos eixos Política Institucional, e Cultura e Formação Geral. No eixo Política Institucional havia temáticas como Balanço e perspectivas para o ano em curso, Biblioteca universitária, Avaliação de impactos sociais em projetos de extensão, Procedimentos acadêmicos na docência - Aspectos Legais. No eixo Cultura e Formação Geral, eram ofertadas outras como Relações étnico-raciais, Música, Fotografia e pictorismo, Novo acordo ortográfico, Artigo científico, História e patrimônio cultural, História da arte brasileira, Literatura e artes visuais, entre outras. Nesta pesquisa, analisamos todas as temáticas ofertadas e identificamos as pedagógicas pela ementa cadastrada.

Há de se considerar que temáticas voltadas à Cultura e Formação Geral oferecem também possibilidades de se ampliar a ação pedagógica e as práticas curriculares, pois resultam de aprendizagens significativas e geram experiências que podem reverberar quando envolvem e afetam o professor e Ihe possibilitam oportunidades de repensar e colocar-se no mundo com autonomia (Kupiec, Neitzel, Carvalho, 2016). Uma temática cultural, voltada à formação estética do professor, pode levá-lo a ver e sentir a sala de aula numa outra perspectiva, mais humana e acolhedora. Essas temáticas tinham grande adesão dos professores e muitos totalizavam sua carga horária na formação apenas no eixo Cultura e Formação Geral. No entanto, apesar de entendermos que essa formação interfere na forma de interagir com o mundo e pode potencializar ações inovadoras de ensino, tornou-se premente garantir uma formação mínima voltada aos saberes da docência, que qualificam as ações em sala de aula porque se voltam diretamente ao pensar e 
fazer pedagógico. Mapeamos, a seguir, a oferta de temáticas que o Programa de Formação Continuada Docente da Univali promoveu de 2011 a 2017, separando-as em duas grandes categorias: pedagógicas e não pedagógicas.

\section{GRÁFICO 4}

Classificação das temáticas oferecidas no Programa de Formação Continuada Docente da Univali 2011-2017

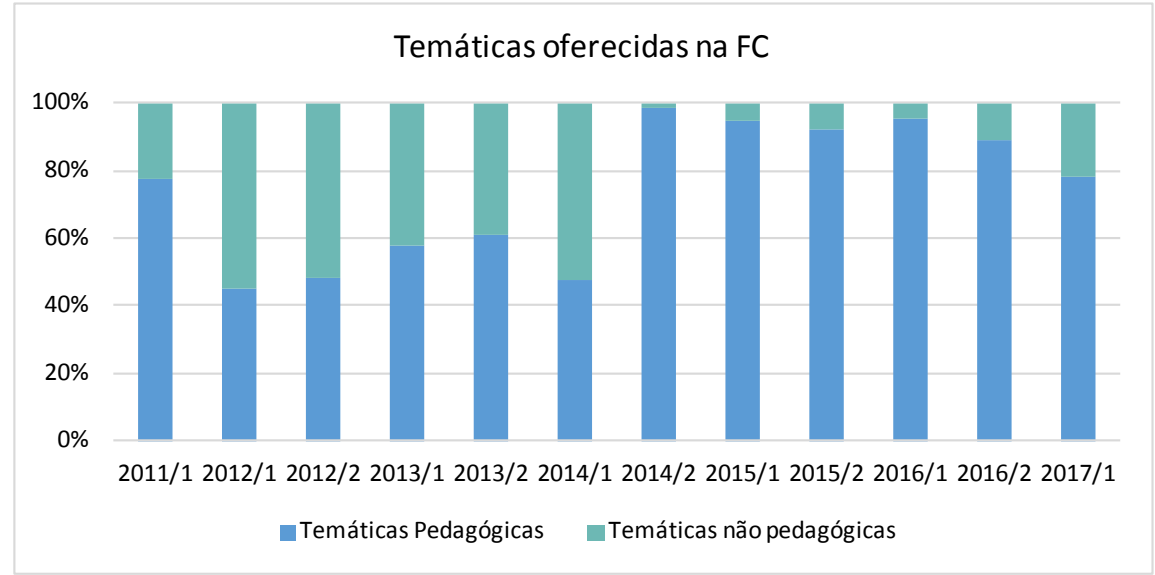

Fonte: UNIVALI, VRG - GEA/2017

Conforme indica o Gráfico 4, no intervalo entre o primeiro semestre de 2011 e o primeiro semestre de 2014, o Programa de Formação Continuada Docente da Univali tinha uma oferta mais ampla de temáticas não pedagógicas, lembrando que nesse período o professor poderia optar pela temática que desejasse. Ainda, precisamos considerar que, até o primeiro semestre de 2014, havia três eixos na formação e o professor poderia optar por fazer apenas as temáticas do eixo não pedagógico.

Diante deste resultado, nos questionamos se os professores estariam priorizando rever e aprimorar suas práticas por meio do programa ou se destinavam esse período de formação para ampliar sua formação geral e cultural. Estariam eles participando de ofertas que os orientassem a organizar seu trabalho em sala de aula? A partir deste questionamento, buscamos identificar quais temáticas os professores investigados escolheram, observando 0 percentual de temáticas pedagógicas.

Observando a carga horária individual de cada professor integrante da amostra no intervalo do primeiro semestre de 2011 ao primeiro semestre de 2017, os dados nos mostram que todos os 69 professores em foco neste estudo fizeram mais carga horária nas temáticas pedagógicas. Podemos inferir que a proposta de temas pedagógicos era de interesse dos professores e que a necessidade formativa guiou suas escolhas. Elas podem revelar as 
dificuldades sentidas pelos docentes assim como o desejo de ampliar seus saberes e partilhá-los. Tendo em vista que o grupo pesquisado tem, no mínimo, 12 semestres de trabalho na universidade, caracterizando-se como um grupo experiente na Educação Superior, é pouco provável que frequente essas temáticas por causa de carência formativa no campo da didática, e sim em razão do reconhecimento da importância desses saberes didáticopedagógicos para a compreensão dos processos de ensino e aprendizagem.

\section{GRÁFICO 5}

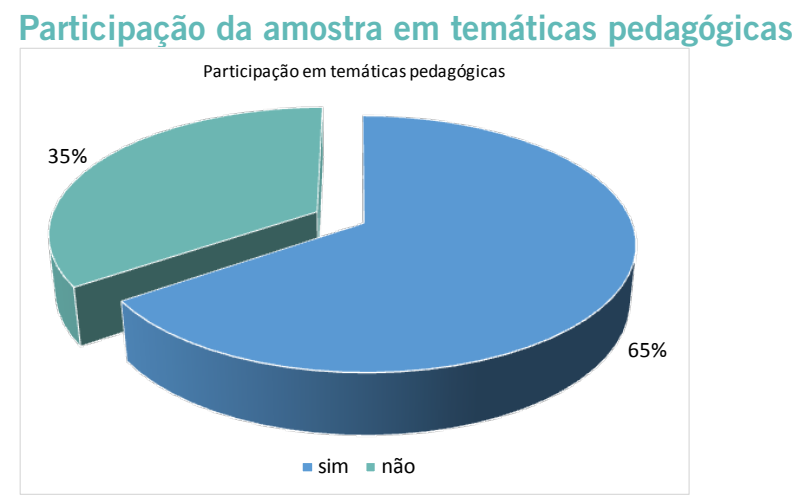

Fonte: UNIVALI, VRG - GEA/2017

A partir do segundo semestre de 2014 , com a reestruturação do programa, tornou-se obrigatória a frequência em pelo menos 8 horas de temáticas pedagógicas e a oferta de outras temáticas passou a ser menor. Consequentemente, ampliou-se a participação dos docentes nas temáticas pedagógicas, como podemos observar pelos gráficos a seguir.

\section{GRÁFICO 6}

Participação em temáticas pedagógicas - do $1^{\circ}$ semestre de 2011 ao $1^{\circ}$ semestre de 2014

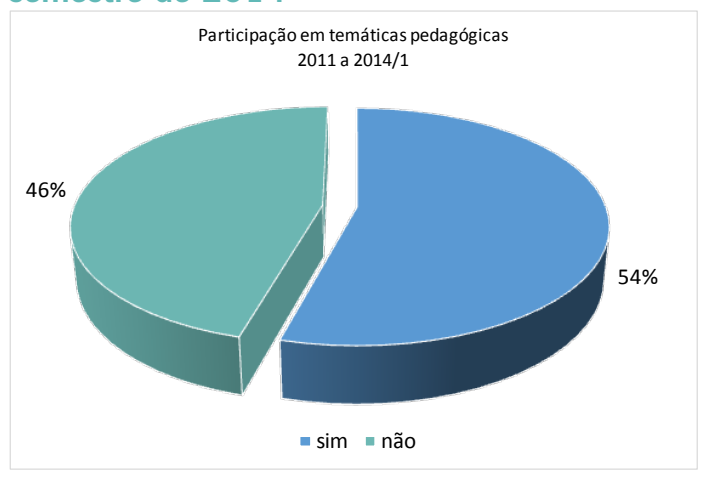

Fonte: UNIVALI, VRG - GEA/2017 


\section{GRÁFICO 7}

\section{Participação em temáticas pedagógicas entre o segundo semestre de 2014} e o primeiro semestre de 2017

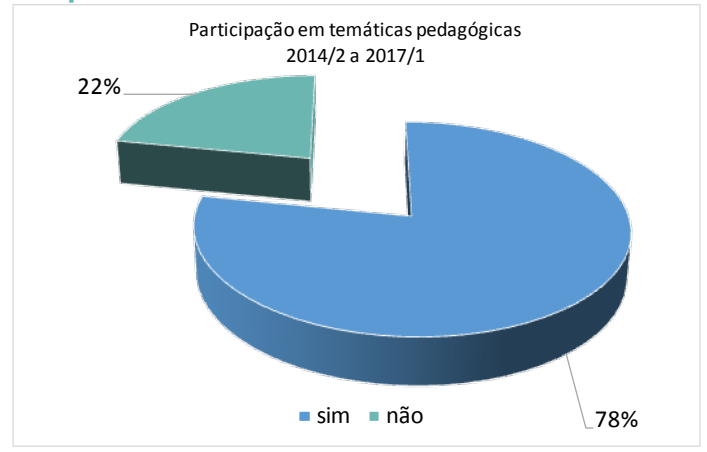

Fonte: UNIVALI, VRG - GEA/2017

Salienta-se que algumas temáticas pedagógicas se repetem e outras não, atendendo a demandas específicas. Aquelas que envolvem o uso de tecnologias em sala de aula, elaboração de planos de ensino, conhecimento do Projeto Pedagógico do Curso, entre outras, são ofertadas em todos os semestres. Já outras, como Tendências curriculares na formação do universitário: a visão dos docentes da UNIVALI; Prova: elaboração de questões objetivas e discursivas, Inovações pedagógicas na Educação Superior - indicadores de qualidade, fazem parte da programação de um determinado semestre e podem ou não ser ofertadas novamente.

A presença constante dos docentes integrantes da amostra nas oficinas de temáticas pedagógicas sinaliza a necessidade de estabelecer interlocuções com seus pares. Ou seja, mesmo professores experientes recorrem a temáticas pedagógicas para melhorarem suas práticas, e não podemos ignorar que esta melhoria passa pela compreensão do que fazem e por que fazem. Para Franco (2016, p.518): "O saber pedagógico só pode se constituir a partir do próprio sujeito, que deverá ser formado como alguém capaz de construção e de mobilização de saberes". Quando um programa de formação permite a articulação entre a teoria educacional e a prática docente, há um refinamento dos saberes e o docente se nutre das experiências de seus pares, reinventa-se e o seu protagonismo é ativado. "Isso só pode ser feito com um sujeito que se sinta, se aperceba como ator de sua história, um sujeito 'empoderado', habilitado ao exercício do poder que advém de suas práxis" (Franco, 2016, p. 517).

Franco (2016, p. 512) afirma que assim como "as teorias por si não formam o professor", a prática repetitiva "docente exercida sem reflexão, sem consciência; sem crítica" pouco contribui. A formação continuada para 
os professores experientes também é um espaço de aperfeiçoamento, pois como Franco (2016, p. 512) sinaliza, "Anos de docência não se transformam automaticamente em saberes da experiência". O caráter formativo e crítico de uma formação se constitui na coletividade, na "construção de consensos coletivos" (Franco, 2016, p. 522).

Nossa pesquisa revela que há um grupo de professores compartilhando temáticas pedagógicas de modo contínuo e que por esse motivo vai se fortalecendo como grupo, um fortalecimento que amplia as referências do professor e seu universo cultural. Na formação, partilham conhecimentos, ajustam modos de agir coerentes com as percepções do grupo, constroem problematizações sobre o aprender e o ensinar, abordam possibilidades de novas situações experienciais, vivem e respiram consensos e desacordos, percebem-se como professores.

\section{CONSIDERAÇÕES FINAIS}

Esta pesquisa nos permitiu refletir sobre a qualidade na Educação Superior por meio de duas políticas públicas: a formação continuada de professores e a avaliação institucional. De modo diferente da Educação Básica, a Educação Superior agrega profissionais de diferentes áreas que não são licenciados e que se constituem professores na ação docente. A instituição que possui um programa de formação continuada qualificado evidencia compromisso e responsabilidade com seu público, porque entende que esta formação não pode ser episódica, mas contínua, um espaço de discussão e trocas. É neste espaço que o professor externa suas dúvidas, suas experiências e encontra respaldo institucional para constituir-se professor. Ao escutar seus pares, reflete sobre sua prática e vai descobrindo outras formas de exercer a docência.

No que diz respeito ao Programa de Formação Continuada da Univali, em foco, identificamos que o índice de participação docente vem aumentando, apesar de a carga horária mínima obrigatória de formação ter diminuído ao longo dos anos: o índice médio de participação, que era de 16 horas no primeiro semestre de 2011 , subiu para 23 horas no primeiro semestre de 2017, revelando uma adesão ao movimento institucional.

Diante deste dado, nos sentimos desafiadas a investigar quais temáticas os docentes priorizaram com o intuito de perceber se suas escolhas se aproximavam ou se distanciavam das temáticas pedagógicas. Reconhecemos que $100 \%$ dos docentes do grupo analisado fizeram mais carga horária nas temáticas pedagógicas. A partir do segundo semestre de 2014, 
com a reestruturação do programa, ampliou-se a participação dos docentes nas temáticas pedagógicas, e o grupo de professores em foco, mesmo sendo experiente, com no mínimo 12 semestres na Educação Superior, ampliou sua carga horária para além da demanda da instituição. Este grupo, ao longo do exercício da docência, continua compartilhando com os pares seus saberes, e este caráter contínuo fortalece-os como grupo, um fortalecimento que amplia o mundo de referência do professor, seu universo cultural.

Com relação à avaliação institucional sobre a atuação do professor, identificamos que a média de avaliação da atuação docente conforme os discentes varia entre 8,3 e 8,7. Dos 69 docentes que fazem parte da amostra, apenas três registram média inferior a sete, ou seja, 95,66\% possuem média superior a 7. Nenhum docente possui média inferior a seis. Esta manifestação dos discentes sobre a atuação desse grupo de professores revela não apenas satisfação com as oportunidades de aprendizagem geradas em sala de aula, mas também que eles se mantêm em reflexão sobre o processo educativo. Avaliar exige reconhecer a intensidade, a força, os pontos frágeis do sujeito avaliado, mas também demonstra a força de quem avalia.

Esta pesquisa surgiu da necessidade de compreendermos o impacto da formação continuada na atuação do professor e por isso buscamos cruzar dados da formação continuada com os da avaliação institucional. Identificamos que o grupo de 69 professores integrantes da amostra frequenta a formação continuada acima da carga horária exigida pela instituição e prioriza as temáticas pedagógicas - os saberes da docência; esse mesmo grupo possui uma avaliação média de 8,3 considerada alta no contexto da Univali. Se esse resultado reflete ou não o movimento formativo no qual o docente está inserido na instituição, não podemos afirmar, porque não utilizamos nenhum instrumento que nos permitisse aferir este dado. Mas, podemos inferir que este grupo de professores se mostrou, ao longo de seis anos, comprometido com a profissionalidade docente, dinamizando em sala de aula os conhecimentos construídos em seu percurso formativo.

\section{REFERÊNCIAS}

Borba, A. (2002). Apresentação do Caderno de Ensino. Formação continuada para docentes do Ensino Superior: apontamentos para novas alternativas pedagógicas. Amândia Maria de Borba, Sueli Petry da Luz (coordenação), Univali, Itajaí.

Castro, C. de M.; Navarro, J. C. (2017). Will the invisible hand fix private higher education in Latin America? Ensaio: aval.pol.públ.Educ. 25(96), p.770-797, jul/set. Rio de Janeiro. 
Ferri, C.; Duarte, B.K. da C.; Neitzel, A. de A.; Uriarte, M. Z., Sousa, N. de. (2017). Relatório de avaliação institucional na educação superior: a atuação do docente em foco. Vice Reitoria de Graduação. Universidade do Vale do Itajaí, SC, Brasil.

Franco, M. A. S. (2016). Pesquisa-Ação Pedagógica: práticas de empoderamento e de participação. ETD - Educação Temática Digital, 18(2), pp. 511-530, abr./jun. Campinas, SP.

Gatti, B. A. (2000). Avaliação institucional e acompanhamento de instituições de educação superior: estudos em avaliação educacional. São Paulo: Fundação Carlos Chagas, vol. 21.

Kupiec, A.; Neitzel, A. de A., \& Carvalho, C. (2016). A mediação cultural e o processo de humanização do homem. In A. Neitzel \& C. Carvalho (Eds), Mediação cultural, formação de leitores \& educação estética (pp. 23-36). Curitiba: CRV.

Nóvoa, A. (2000). Universidade e formação docente. Interface - Comunic, Saúde, Educ. [online], Botucatu, vol.4, n.7, aug. Entrevista concedida às professoras Miriam Celí Pimentel Porto Foresti e Maria Lúcia Toralles Pereira. http://dx.doi.org/10.1590/ S1414-32832000000200013.

Nunes, E. B. L. de L. P.; Trombini, M. M. S. L. D.; Pereira, I. C. A. (2017). Planejamento e avaliação institucional: um indicador do instrumento de avaliação do SINAES. Avaliação, 22(2), pp. 373-384, jul. Campinas; Sorocaba, SP.

Pryjma, M. F.; Oliveira, O. S. de. (2016). O desenvolvimento profissional dos professores da educação superior: reflexões sobre a aprendizagem para a docência. Educ. Soc. 37(136), pp 1-17, jul/set. Campinas.

Sá, E. F.; Quadros, A. L. de; Mortimer, E. F.; Silva, P. S.; Talim, S. L. (2017). As aulas de graduação em uma universidade pública federal: planejamento, estratégias didáticas e engajamento dos estudantes. Rev. Bras. Educ. 22(70), pp. 625-650, jul/set. Rio de Janeiro. https://dx.doi.org/10.1590/s1413-24782017227032

Stano, R. de C. M. T. (2015). O caminho de um grupo de formação continuada docente: do compartilhamento de práticas docentes para uma pedagogia da e para a autonomia. Educar em Revista, n. 57, p. 275-290, jul./set. Curitiba. 
